\title{
DETERMINACIÓN DE PARENTESCO EN ALPACAS (Vicugna pacos) POR MEDIO DEL ANÁLISIS DE ADN MICROSATÉLITE
}

\author{
Jorge Rodríguez B. ${ }^{1}$, Jane C. Wheeler ${ }^{1,2}$, Ciara S. Dodd ${ }^{3}$, Michael W. Bruford ${ }^{3}$ y \\ Raúl Rosadio A. ${ }^{1,4}$
}

\section{AbStRaCt}

Ten polymorphic microsatellites for alpacas and llamas were used to evaluate paternity in 47 alpacas (18 crias, 18 mothers and 11 fathers) registered at IVITA-Maranganí Research Station, Canchis Province (Cusco-Peru). Analysis was carried out using two methodologies: Automatic Sequencer (ABI 377 DNA sequencers $\left.{ }^{\circledR}\right)$ and silver staining techniques. Microsatellites were amplified in three multiple and ten single PCR reactions. The number of alleles varied between 4 and 20. The allelic frequencies and the exclusion probability were calculated using Cervus 2.0. All loci, except for two, were within the range published elsewhere. The accumulated exclusion probability for the ten loci was 0.9999 . For each multiplex reaction the accumulated exclusion probability was more than 0.90 . Both methodologies yielded the same results. The results confirmed paternity in 18 cases of parent-cria pairs, however in $22 \%$ of cases $(n=4)$ were identified alternative parents than those indicated in farm records.

Key words: alpaca, microsatellites, paternity

\section{Resumen}

Diez microsatélites polimórficos para alpacas y llamas fueron usados para evaluar el parentesco en 47 alpacas (18 crías, 18 madres y 11 padres) de la Estación Experimental IVITA-Maranganí, provincia de Canchis (Cusco, Perú). El análisis se llevó a cabo utilizando dos metodologías: secuenciador automático (ABI 377 DNA sequencers $囚)$ y técnica de tinción con nitrato de plata. Los microsatélites fueron amplificados en tres reacciones de PCR múltiple y diez reacciones de PCR simple. El número de alelos varió entre 4 y 20. Las frecuencias alélicas y la probabilidad de exclusión (PE) fueron calculadas utilizando el software Cervus 2.0. Todos los loci, a excepción de dos, se encontraron dentro de los rangos encontrados en la literatura. La probabilidad de exclusión acumulada para los 10 loci fue 0.9999. La probabilidad de exclusión acumulada para cada reacción de PCR múltiple fue mayor a 0.90 . Ambas metodologías obtuvieron los mismos resultados. Los resultados confirmaron la paternidad en 18 casos; sin embargo en el $22 \%$ de los casos $(n=4)$ se identificaron padres alternativos que no correspondieron a los padres registrados.

Palabras clave: alpaca, microsatélites, paternidad

\footnotetext{
${ }^{I}$ CONOPA

${ }^{2}$ E-mail: webmaster@conopa.org

${ }^{3}$ Department of Biodiversity and Ecological Processes, Cardiff University, Cardiff, U.K.

${ }^{4}$ Laboratorio de Microbiología y Parasitología Veterinaria, FMV-UNMSM

Email:rrosadioa@vetunmsm.edu.pe; rrosadio@terra.com.pe
} 


\section{INTRODUCCIÓN}

Métodos precisos para identificación y verificación de parentesco son de gran importancia para los criadores de animales domésticos, así como para el establecimiento de registros y libros genealógicos. Por muchos años, los métodos convencionales, tales como la tipificación de grupos sanguíneos y polimorfismos bioquímicos han sido las únicas herramientas utilizadas para dicho fin. Durante la pasada década se han desarrollado técnicas basadas en ADN y puestas en práctica mediante la técnica de la reacción en cadena de la polimerasa (PCR). Entre estas técnicas se encuentra el análisis de ADN microsatélite.

Los microsatélites, comúnmente conocidos como repeticiones cortas en serie (STRs), son secuencias cortas (no mayores de 6 pares de bases de largo) repetidas en serie (Hancock, 1991) que pueden ser amplificados por la técnica de PCR y los distintos alelos observados por medio de electroforesis en gel y posterior teñido con nitrato de plata o por marcado con sustancias fluorescentes.

En países como EE.UU, Canadá, Reino Unido y Australia, el ingreso de camélidos a libros de registro se basa en el análisis de ADN (microsatélites) para identificación individual y de parentesco. En el Perú, a diferencia de estos países, se cuenta con un libro de registro que acredita la descendencia de los animales inscritos, por medio de técnicas que tienen un grado de certeza muy inferior a las obtenidas por pruebas genéticas aceptadas en países con mayor desarrollo tecnológico. Por lo tanto, se vuelve necesario contar con una prueba de análisis de ADN de alta confiabilidad, de costo moderado y que pueda ser aplicado en forma masiva con la tecnología disponible en el país.

\section{Materiales y Métodos}

Se colectó sangre de 47 alpacas (Vicugna pacos) previamente identificadas
(11 padres, 18 madres y 18 crías) en los registros de la Estación Experimental del IVITA-Maranganí, para la prueba de determinación de parentesco. El Centro Experimental se encuentra en el distrito de Maranganí, provincia de Canchis, departamento de Cusco, y los análisis se realizaron en las instalaciones de la Unidad de Virología y Genética Molecular de la Facultad de Medicina Veterinaria de la Universidad Nacional Mayor de San Marcos, Lima, y en la Unidad de Biodiversidad y Procesos Ecológicos de la Universidad de Cardiff, Gales, Reino Unido.

El ADN genómico fue extraído de la sangre utilizando el ULTRACLEAN DNA BloodSpin Kit ${ }^{\circledR}$ (Mo Bio Inc) de acuerdo a las instrucciones del fabricante. La calidad (tamaño del fragmento) y la cantidad (concentración) del ADN fue determinada comparando diluciones seriadas de un marcador de peso molecular (D)A Hind III ${ }^{\circledR}$, AMRESCO a una concentración de $50 \mathrm{ng} / \mu \mathrm{l}$ en un gel de agarosa al $0.8 \%$.

Los diez loci microsatélite (LCA19, LCA22, LCA5, LCA23, YWLL08, YWLL29, YWLL36, YWLL40, YWLL43, YWLL46) designados para llama (Lama glama) y alpaca, descritos por Lang et al. (1996) y Penedo et al. (1998) fueron amplificados por medio de la técnica de reacción en cadena de la polimerasa (PCR) en un termociclador modelo 9700 GeneAmp ${ }^{\circledR}$ (Perkin Elmer) mediante dos métodos. El primero consistió en tres reacciones de PCR múltiple (amplificación de más de un locus por reacción de PCR) y su análisis mediante un sistema automatizado (ABI 377 DNA sequencers $\AA$ ); y el segundo consistió en diez reacciones de PCR de locus simple (amplificación de un solo locus por reacción de PCR) y su análisis mediante un sistema no automatizado de tinción con nitrato de plata (Bassam et al., 1991).

La asignación de paternidad fue dada por exclusión, observando incompatibilidades entre los tamaños de alelos del padre, de la madre y de las crías, para lo cual se estable- 
ció el poder de la prueba de parentesco por medio de la probabilidad de exclusión individual y acumulada descritas por Jamieson y Taylor (1997). Para el análisis de la probabilidad de exclusión individual y acumulada, la heterocigocidad observada y el contenido de información polimórfica (PIC) se utilizó el software Cervus 2.0 Parentage Analysis (C).

\section{Resultados y Discusión}

La determinación de parentesco o paternidad por medio del análisis de microsatélites está difundido en muchas de las especies domésticas y es utilizada con frecuencia en animales silvestres. Los elevados índices de confiabilidad permiten el uso de microsatélites en estudios de paternidad en caninos con $92 \%$ de certeza (Morera et al., 1999; Pádár et al., 2001), bóvidos domésticos y silvestres con porcentajes cercanos al 100\% (Kankan y Fado, 1999; Mommens et al., 1998), equinos con niveles cercanos al $100 \%$ (Binns et al., 2000) y en primates no humanos con $99 \%$ de certeza (Constable et al., 2001; Vigilant et al., 2001). Similares aplicaciones se observan en camélidos, donde Sasse et al. (2000) y Sam et al. (2001) demostraron la factibilidad de realizar pruebas de paternidad en camellos (Camelus dromedarius) y Skidmore et al. (1999) en paternidad de híbridos de camello y guanaco.

La disponibilidad de información sobre ADN microsatélite en camélidos sudamericanos permitió diseñar el presente estudio, en el cual se eligieron diez microsatélites específicos y altamente polimórficos para camélidos sudamericanos. En el estudio se encontró que los diez microsatélites analizados amplificaron y presentaron polimorfismo en alpacas, con un número de alelos que varió entre cuatro para el locus LCA22, YWLL46 y 20 para el locus YWLL08, con un promedio de 9.1 alelos por locus; resultados similares a los publicados por Lang et al. (1996) y Penedo et al. (1998) aunque con ligeras variaciones en el YWLL08 y el YWLL36, posiblemente debido al distinto origen de los animales.
La probabilidad de exclusión hallada para cada loci microsatélite varió entre 0.174 para el YWLL46 y 0.844 para el YWLL08, mostrando diferencias considerables en los microsatélites YWLL29, YWLL40, YWLL46, YWLL08 y YWLL36 (diferencia mayor o menor al 0.1) con respecto a lo publicado por Lang et al. (1996) y Penedo et al. (1998). La probabilidad de exclusión acumulada para los 10 microsatélites fue 0.9999 . Las tres reacciones PCR múltiple obtuvieron una elevada probabilidad de exclusión combinada (>0.90). Además, se identificaron cuatro microsatélites altamente informativos basados en su alta probabilidad de exclusión individual (YWLL08, YWLL36, LCA23 y YWLL29). La probabilidad de exclusión individual y acumulada para los diez loci microsatélite así como para las tres PCRs múltiples se muestran en el Cuadro 1.

Los análisis de exclusión de paternidad determinaron cuatro errores (22\%) en la asignación de paternidad de los 18 casos evaluados en base a los registros de la Estación Experimental IVITA-Maranganí. Se encontró, además, un caso en el cual no se pudo determinar el verdadero padre debido a su ausencia en las muestras colectadas, lo cual demuestra la importancia del uso de pruebas moleculares en la determinación de parentesco.

Una limitante para el análisis de microsatélites en el país, es la dificultad de uso de equipos de análisis automatizados en forma rutinaria, los que se encuentran limitados a pocas instituciones de investigación debido a su elevado costo. En el estudio se utilizaron dos metodologías: un análisis automatizado (secuenciador automático) y un análisis convencional (tinción con nitrato de plata) obteniéndose los mismos resultados, lo cual hace posible utilizar un sistema de análisis convencional en estudios de determinación de paternidad (Figs. 1 y 2). Se debe precisar que la técnica de tinción con nitrato de plata tiene como limitante que analiza un sólo microsatélite por reacción de PCR, alargando el tiempo del análisis; sin embargo, se obser- 


\section{LCA 23}

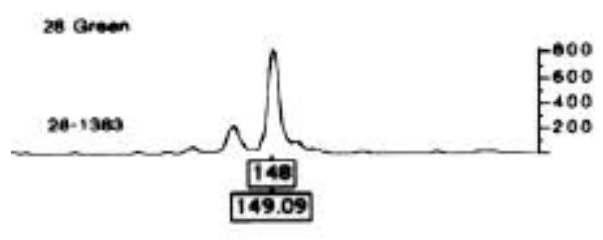

31 Groen
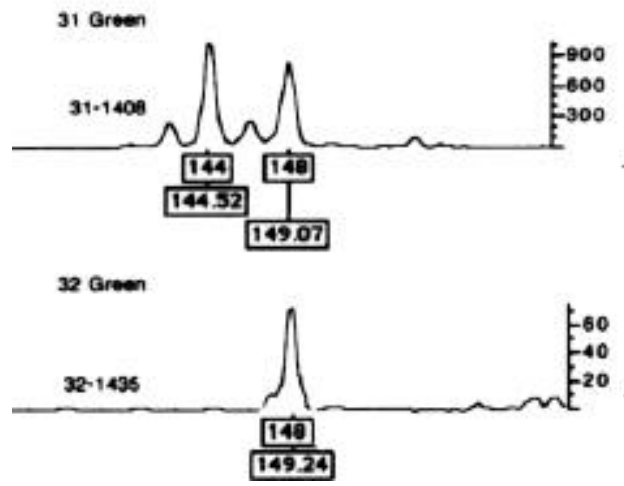

\section{LCA 22}
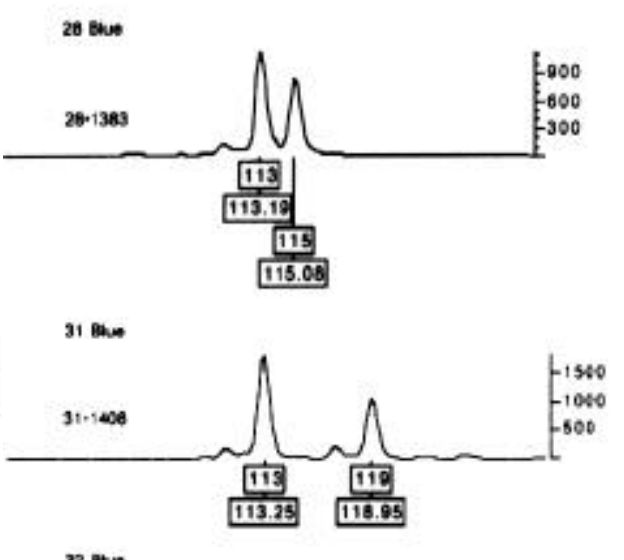

\section{YWLL 36}
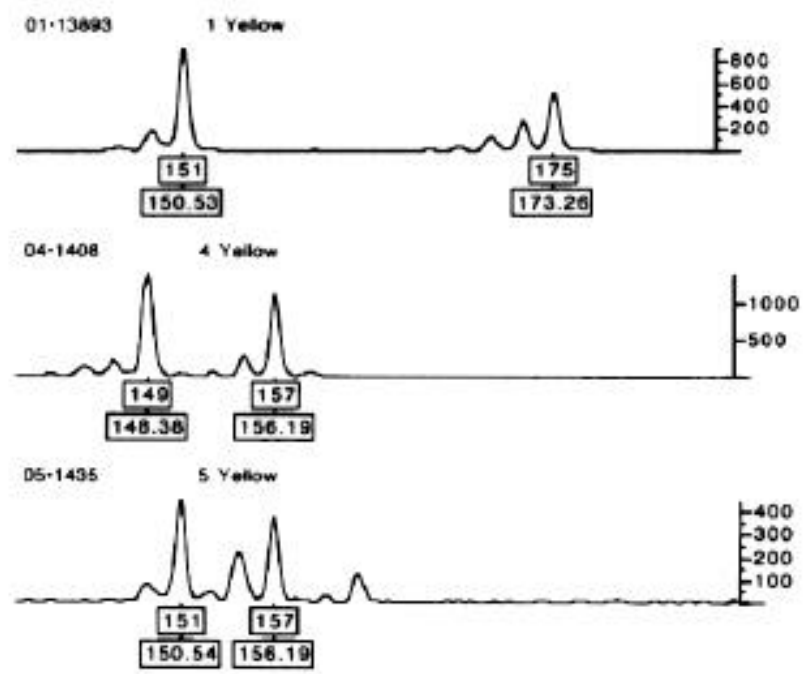

Figura 1. Lectura de los loci LCA23, LCA22 y YWLL36 de alpacas utilizando el software GeneScan 2.1 y Genotyper 2.5 (ABI PRISM)

(a) Lectura del locus LCA23 marcado con el colorante TET (verde). Los números 28, 31 y 32 corresponden a las muestras 1383 (Padre), 1408 (Madre) y 1435 (Cría). Nótese que la cría (homocigoto para el alelo 148) comparte un alelo con el padre (148) y otro con la madre (148).

(b) Lectura del locus LCA22 marcado con colorante FAM (azul).

(c) Lectura del locus YWLL36 marcado con el colorante HEX (amarillo). A la derecha se observa el rango de intensidad de fluorescencia. 
Cuadro 1. Heterocigocidad observada $\left(\mathrm{H}_{(\mathrm{o})}\right)$, contenido de información polimórfica (PIC) y probabilidad de exclusión individual (PE) y acumulada (PEa) de microsatélites utilizados para determinar parentesco y paternidad en alpacas

\begin{tabular}{cccccc}
\hline PCR Múltiple & Microsatélites & $\mathrm{H}_{(\mathrm{o})}$ & PIC & PE & PEa \\
\hline \multirow{3}{*}{ M1 } & LCA 19 & 0.702 & 0.709 & 0.548 & 0.9191 \\
& YWLL 29 & 0.787 & 0.786 & 0.634 & \\
& YWLL 40 & 0.660 & 0.604 & 0.408 & \\
& YWLL 46 & 0.383 & 0.307 & 0.174 & \\
& & & & & \\
M2 & LCA 23 & 0.638 & 0.779 & 0.621 & 0.9286 \\
& LCA 22 & 0.511 & 0.477 & 0.294 & \\
& YWLL 36 & 0.894 & 0.852 & 0.733 & \\
& & & & & 0.9637 \\
M 3 & LCA 5 & 0.809 & 0.744 & 0.575 & \\
\hline M1 + M2 + M3 & YWLL 08 & 0.915 & 0.918 & 0.844 & \\
\hline
\end{tabular}

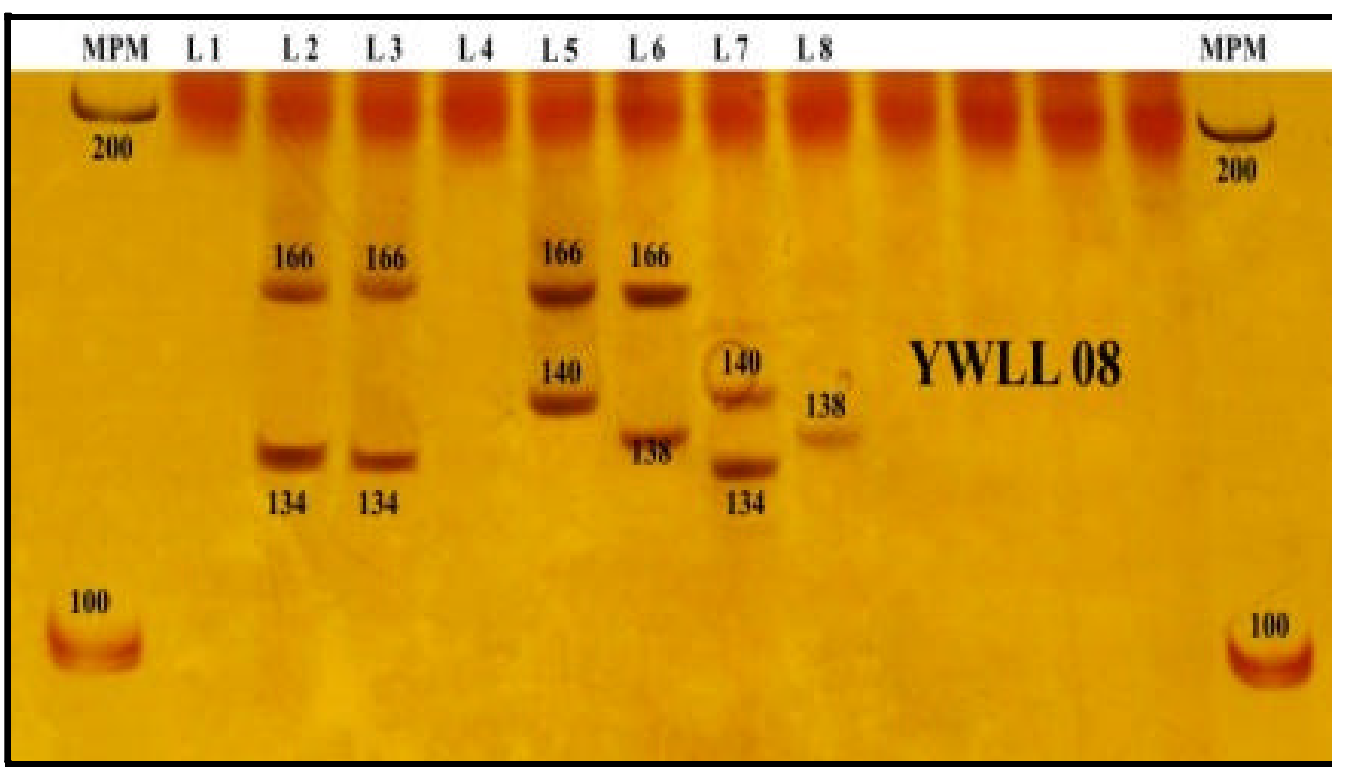

Figura 2. Lectura del locus YWLL 08 de alpacas para la determinación de parentesco utilizando la técnica de tinción con nitrato de plata (Uso de PCR simple).

Lectura del locus YWLL 08 para la obtención de patrones alélicos. MPM = Marcador de Peso Molecular (Eco1471/Pvul) L1 = Blanco, L2 = Patrón alelos 134 y 166, L3 = Alegado Padre 2, L4 = Blanco, L5 = Cría, L6= Madre, L7 = Verdadero Padre y L8 = Patrón alelo 138. 
vó la factibilidad del uso de PCR múltiple (más de un microsatélite) en geles teñidos con nitrato de plata, para microsatélites con grandes diferencias de tamaño de sus alelos, permitiendo disminuir el tiempo y los costos de la prueba.

Éste es el primer estudio a nivel molecular diseñado en el país para pruebas de parentesco en camélidos sudamericanos, siendo posible su aplicación en llamas y camélidos silvestres con los marcadores microsatélites utilizados.

\section{Conclusiones}

? Se demostró la factibilidad del uso de ADN microsatélite (diez microsatélites) para la determinación de parentesco con una elevada probabilidad de exclusión (0.9999).

? Con el uso de sólo tres microsatélites (YWLL43, LCA5 y YWLL08) en una reacción de PCR múltiple es posible determinar parentesco con una probabilidad de exclusión aceptable (0.9637).

? Es posible extrapolar los resultados obtenidos mediante el uso de un equipo de secuenciamiento automático (ABI 377 DNA sequencers® Applied Biosystems) con la metodología de tinción de plata, con la diferencia del uso de un solo locus por reacción de PCR.

\section{Agradecimiento}

Los autores agradecen a la Iniciativa Darwin del Gobierno Británico y CONOPA (Perú) por el financiamiento y soporte tecnológico utilizado en este trabajo de investigación; al Ing. Zootec. Juan Olazábal (IVITA-Maranganí) por el apoyo en la toma de muestras, a la MV Rosa Dávalos (IVITA-Huancayo) y a la MV Matilde Fernández por estudios preliminares al presente trabajo. Así mismo, a las autoridades y personal del IVITA-Maranganí por permitir la colección de muestras y apoyo logístico.

\section{Literatura Citada}

1. Bassam, B.J.; G. Caetano-Anolles; P.M. Gresshoff. 1991. Fast and sensitive silver staining of DNA in polyacrilamide gels. Ann. Biochem. 19: 680-683.

2. Binns, M.; J. Swinburne; M. Breen. 2000. Molecular genetics of the horse. En: The genetics of the horse. $p$ 109-121 A. Bowling; A. Ruvinsky (eds). CABI Publishing. London.

3. Constable, J.; M. Ashley; J. Goodall; A. Pusey. 2001. Noninvasive paternity assignment in Gombe chimpazees. Molecular Ecology 10: 1279-1300.

4. Hancock, J. 1991. Microsatellites and other simple sequences: genomic context and mutational mechanisms. En: Microsatellites. Evolution and applications. p 1-9. Goldstein D; C. Schlötterer (eds). Oxford University Press. Oxford.

5. Jamieson, A.; C.S. Taylor. 1997. Comparisons of three probability formulae for parentage exclusion. Animal Genetics 28: 397-400.

6. Kankan, D.; M. Fado. 1999. Estimations of the efficacy and reliability of paternity assignments from DNA microsatellite analysis of multiple-sire matings. Animal Genetics 30: 355-361.

7. Lang, K.; Y. Yang; Y. Plante. 1996. Fifteen polymorphic dinucleotide microsatellites in llamas and alpacas. Animal Genetics 27: 285-294.

8. Mommens, G.; A. Van Zeveren; L. Peelman. 1998. Effectiveness of bovine microsatellites in resolving paternity cases in American bison, Bison bison L. Animal Genetics 29: 12-18.

9. Morera, L.; D.F. De Andrés; M. Barbancho; J.J. Garrido; C.J. Barba. 1999. Detección de variabilidad genética por microsatélites en el Alano Español. Archivos de Zootecnia 48: 63-70. 
10. Pádár, Z.; B. Egyed; K. Kontadakis; L. Zöldág; S. Fekete. 2001. Resolution of parentage in dogs by examination of microsatellites after death of putative sire: case report. Acta Veterinaria Hungarica 49: 269-273.

11. Penedo, C.; R. Caetano; I. Cordova. 1998. Microsatellite markers for South American camelids. Animal Genetics 29: 398-413.

12. Sam, C.; J. Schaaf; C. Lauk. 2001. Improved breeding in camelids through molecular techniques: Development of STR multiplexes for identification and parentage verification. En: Progress in South American Camelids Research. Proceedings of the $3^{\text {d }}$ European Symposium and SUPREME European Seminar. p 296-302. EAAP Publication
$\mathrm{N}^{\circ}$ 105. Gerken M.; C. Reniere (eds). Göttingen.

13. Sasse, J.; M. Mariasegaram; M. Jahabar Ali; S. Pullenayegum; $R$. Babu; J. Kinne; U. Wernery. 2000. Development of a microsatellite parentage and identity verification test for dromedary racing camels. Abstracts of the $27^{\text {th }}$ Conference of the International Society of Animal Genetics (ISAG). Mineappolis, EE.UU.

14. Skidmore, J.; M. Billah; M. Binns; $R$. Short; W. Allen. 1999. Hibridizing old and new world camelids: Camelus dromedaries x Lama guanicoe. Proc. R. Soc. Lond. B 266: 649-656.

15. Vigilant, L.; M. Hofreiter; H. Siedel; C. Boesch. 2001. Paternity and relatedness in wild chimpanzee communities. PNAS 98: 12890-12895. 